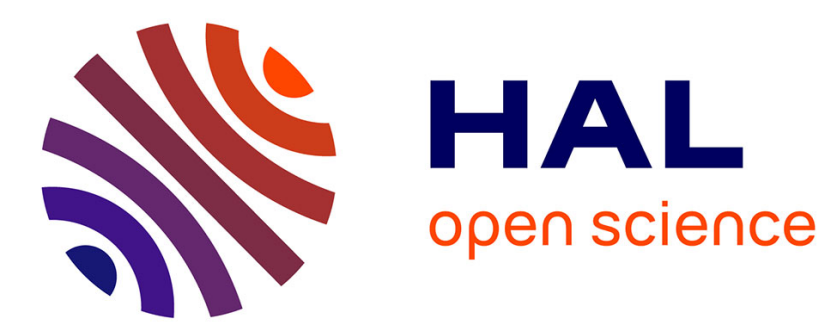

\title{
Pickering emulsions assisted synthesis of fatty acetal over phenyl sulfonic groups grafted on activated charcoal
}

Minrui Xu, Frédéric Richard, Matthieu Corbet, Philippe Marion, Jean-Marc

Clacens

\section{- To cite this version:}

Minrui Xu, Frédéric Richard, Matthieu Corbet, Philippe Marion, Jean-Marc Clacens. Pickering emulsions assisted synthesis of fatty acetal over phenyl sulfonic groups grafted on activated charcoal. Applied Catalysis A : General, 2020, 597, pp.117543. 10.1016/j.apcata.2020.117543 . hal-02536516

\author{
HAL Id: hal-02536516 \\ https://hal.science/hal-02536516
}

Submitted on 8 Apr 2020

HAL is a multi-disciplinary open access archive for the deposit and dissemination of scientific research documents, whether they are published or not. The documents may come from teaching and research institutions in France or abroad, or from public or private research centers.
L'archive ouverte pluridisciplinaire HAL, est destinée au dépôt et à la diffusion de documents scientifiques de niveau recherche, publiés ou non, émanant des établissements d'enseignement et de recherche français ou étrangers, des laboratoires publics ou privés. 


\section{Pickering emulsions assisted synthesis of fatty acetal over phenyl sulfonic groups grafted on activated charcoal}

Minrui Xu${ }^{1}$, Frédéric Richard ${ }^{1}$, Matthieu Corbet $^{2}$, Philippe Marion², Jean-Marc Clacens ${ }^{1, *}$

${ }^{1}$ Institut de Chimie des Milieux et Matériaux de Poitiers, UMR 7285 Université de Poitiers CNRS, 4 rue Michel Brunet, BP633, 86022 Poitiers Cedex, France.

${ }^{2}$ Solvay Research \& Innovation Center of Lyon, 85 rue des Frères Perret, BP 62 69192, Saint Fons, France.

Corresponding authors:

jean-marc.clacens@univ-poitiers.fr

\section{Keywords:}

Green Chemistry $\bullet$ Pickering Interfacial Catalysis $•$ Acid Catalysis $•$ Acetalization $\bullet$ Biphasic Catalysis 


\begin{abstract}
:
Activated charcoal Darco ${ }^{\circledR} \mathrm{KB}-\mathrm{G}$, was functionalized with phenyl sulfonic groups $\left(\mathrm{Ph}_{-} \mathrm{SO}_{3} \mathrm{H}\right)$ by surface modification in acidic aqueous media under mild conditions $\left(25^{\circ} \mathrm{C}, \mathrm{P}_{\mathrm{atm}}\right)$. The formation of new C-C covalent bonds was confirmed by both TGA and XPS. The functionalized amphiphilic solids were also characterized by nitrogen adsorption-desorption, SEM, IR and Raman spectroscopy. The reference solid Darco-0.50ASFL stabilized dodecyl aldehyde/ethylene glycol by Pickering emulsions and demonstrated both good activity and selectivity in a solvent-free biphasic acetalization. Kinetic studies of the formation of hemiacetal and acetal were investigated by monitoring the progress of the reaction by HPLC. Experimental kinetic profiles of dodecyl aldehyde, hemiacetal and acetal were compared to model kinetic profiles. The recycling of Darco-0.50ASFL was also studied by performing five consecutive catalytic runs without regeneration of the catalyst.
\end{abstract}




\section{Introduction:}

Mineral acids, such as $\mathrm{H}_{2} \mathrm{SO}_{4}, \mathrm{H}_{3} \mathrm{PO}_{4}$ and $\mathrm{HF}$ can be used as homogenous acid catalysts for several applications. Nevertheless, these acids are generally corrosive and cannot be recycled at the end of the involved chemical process. Moreover, these homogeneous catalysts have to be neutralized, thereby making the process polluting. In consequence, the development of environmentally sustainable approaches to chemical processes have stimulated the replacement of these mineral acids by recyclable solid acids, limiting the environmental issues and reducing the production costs because of easier products separation [1].

Both silica and carbonaceous materials can be used for the synthesis of heterogeneous acid catalysts. Silica materials are easier to be functionalized because of their sufficient amounts of functionalities on the surface compared to carbonaceous materials. However, the Si-O bond is easier to be broken in basic or acidic media than the $\mathrm{C}-\mathrm{C}$ bond. Mbaraka et al. demonstrated that silica based solid acids could be obtained by simultaneous hydrolysis and condensation of tetraethoxysilane (TEOS) with (3-mercaptopropyl)trimethoxysilane (MPTMS) in the presence of different surfactant templates, using in situ oxidation of thiol groups with $\mathrm{H}_{2} \mathrm{O}_{2}$ [2]. The hydrophilic lipophilic balance (HLB) of these solids could be modified by further incorporation of hydrophobic organic groups via postsynthesis grafting [3]. These silica based solid acids were evaluated in esterification of fatty acids with methanol to produce methyl esters. It was shown that these functionalized silica showed higher activity than commercial acid catalysts such as Amberlyst-15 and Nafion. However, the hydrophilic surface of silica favored the adsorption of water, a byproduct in esterification, and hence led to the deactivation of catalyst.

The relative stability of carbon compared to silica indicates that the formation of new C-C covalent bonds on the surface of carbon is inherently difficult due to the high bond strength of carbon and the impossibility to have common pathways such as $\mathrm{S}_{\mathrm{N}} 2$ mechanisms at surfaces of solid materials [4]. However, carbon is not totally inert due to the presence of unsaturated valances at the edges and defects of the graphitic hexagonal crystallites [5]. During the past few years, the functionalization of carbonaceous materials has been widely developed because carbon is an inexpensive and extensively available material. The choice of carbonaceous materials can be activated charcoal [6-8], ordered mesoporous carbon $[9,10]$, carbon black [11], carbon nanofibers [12] and graphene oxide [13]. It is also possible to generate carbon-based materials from lignocellulosic biomass either by hydrothermal carbonization technic (HTC) [14-19] or solvothermal carbonization technic [20]. The functionalization of carbonaceous 
materials to solid acids is usually carried out by acid treatment with concentrated $\mathrm{H}_{2} \mathrm{SO}_{4}$ or fuming $\mathrm{SO}_{3}[6,14-17,20]$, and by chemical reduction of aryl diazonium salts [7-12].

For examples of acid treatment, Toda et al. reported a carbon-based solid acid catalytic system by sulfonating incompletely carbonized saccharides [14]. The catalyst synthesis was performed under harsh reaction conditions, including high temperature of pyrolysis $\left(>300{ }^{\circ} \mathrm{C}\right)$ and sulfonation $\left(150^{\circ} \mathrm{C}\right)$. Indeed, the hydrothermal carbonization technic (HTC) is generally beset with several disadvantages such as high temperature and evolution of voluminous harmful gases during the pyrolysis step [20]. Due to this, Onda et al. avoided the synthesis of carbonaceous materials from pure carbohydrates and purchased activated charcoal powder to carry out the sulfonation [6]. Their sulfonated material based on activated charcoal showed both good activity and selectivity for the glucose production from cellulose. Compared to the corrosive acid treatment, chemical reduction of aryl diazonium salts seems to be more environmentalfriendly since the sulfur-containing reactant is sulfanilic acid which is less corrosive than $\mathrm{H}_{2} \mathrm{SO}_{4}$ and $\mathrm{ClSO}_{3} \mathrm{H}$. Furthermore, high temperature is not necessary during the process because the functionalization is generally carried out between a range from $0[7,9,10,13]$ to $70{ }^{\circ} \mathrm{C}[8,12]$. Wang et al. [9] reported that hypophosphorous acid $\left(\mathrm{H}_{3} \mathrm{PO}_{2}\right)$ was used during the reduction process to convert diazonium salts to corresponding aryl radicals according to the reduction mechanism proposed by Kornblum et al.[21] whereas it was also suggested that the use of hypophosphorous acid $\left(\mathrm{H}_{3} \mathrm{PO}_{2}\right)$ was not indispensable because carbon surface was reductive enough to reduce aryl diazonium salts by itself $[22-28,11,29,30]$. Although the formation of diazonium cations was clearly understood, the mechanism of diazonium reduction by reductive surface of carbonaceous materials is still under debate. Up to now, the Gomberg-Bachmann mechanism remains the most accepted, in which the reduction occurs via electron transfer from carbonaceous materials into diazonium species, releasing $\mathrm{N}_{2}$ and forming a reactive radical that reacts with carbonaceous materials to form arene bonds [31].

Pickering Interfacial Catalysis (PIC) is a very promising strategy to solve problems associated with the treatment of organic solvent. This ecological and efficient concept offers an elegant solution to overcome diffusion limitations in liquid/liquid reactions [32]. With the PIC technic, reactions can be carried out in a liquid/liquid biphasic system without organic solvent by means of both amphiphilic and catalytic nanoparticles. The search for these versatile nanoparticles to perform chemical reactions in an eco-compatible and ecological way remains at the heart of green chemistry. Recently, solids acting as both catalyst and emulsifier were functionalized from silica and carbonaceous materials. Zhou et al. [33] developed amphiphilic silica nanoparticles while Fang et al. [19] designed a carbonaceous solid acid through hydrothermal 
carbonization of polysaccharides with Aquivion ${ }^{\circledR}$ perfluorosulfonic superacid at $180{ }^{\circ} \mathrm{C}$. These two functionalized solids behaved as efficient acid heterogeneous catalysts in a solvent-free acetalization of immiscible long-chain aldehydes with ethylene glycol, leading to acetal productivity up to $2000 \mathrm{mmol}\left(\mathrm{mmol} \mathrm{H}^{+}\right)^{-1}$ for silica based solids or $900 \mathrm{mmol}\left(\mathrm{mmol} \mathrm{H}^{+}\right)^{-1}$ for carbon based solids, after $1 \mathrm{~h}$ of reaction at $60^{\circ} \mathrm{C}$ and $45^{\circ} \mathrm{C}$, respectively.

In the current progress to environment-friendly solid acids, it would be highly desirable to synthesize catalysts from costless starting materials by a simple procedure with few unitary operations avoiding the use of organic solvents. Herein, we report a total organic solvent-free procedure to synthesize a long chain acetal from the design of carbon based acid catalysts to the catalytic application using a simple and green synthetic method.

\section{Experimental part:}

\subsection{Materials}

Activated charcoal Darco ${ }^{\circledR}$ KB-G was purchased from Sigma-Aldrich. Ethylene glycol (noted as EG, 99\%), dodecyl aldehyde (noted as D, >98\%), 2-methyltetrahydrofuran (noted as 2-MTHF, $>99 \%$ ) and toluene anhydrous (99.8\%), all supplied by Alfar Aesar, were used for carrying out the acetalization reaction. Finally, toluene anhydrous (99.8\%) was used as internal standard in the HPLC analytical tests. p-toluenesulfonic acid monohydrate (PTSA, 98.5\%, Sigma-Aldrich) was used as reference and the benchmark catalyst. Sulfanilic acid (noted as ASFL, 99\%), sodium nitrite $\left(\mathrm{NaNO}_{2}, 99 \%\right)$ and hydrochloric acid ( $\left.\mathrm{HCl}, 37 \%\right)$ were purchased from Sigma-Aldrich and used in the functionalization of Darco ${ }^{\circledR}$ KB-G. All the materials were used as received without further purification.

\subsection{Preparation of Darco-0.50ASFL}

$0.5 \mathrm{~g}$ of sulfanilic acid (1 eq; $2.86 \mathrm{mmol})$ and $0.4 \mathrm{~g}$ of sodium nitrite $\left(\mathrm{NaNO}_{2}, 2 \mathrm{eq} ; 5.72\right.$ mmol) were dissolved in $100 \mathrm{~mL}$ of distilled water with vigorous stirring. $1 \mathrm{~g}$ of activated charcoal was then dispersed in the solution followed by the dropwise addition of hydrochloric acid ( $4 \mathrm{~mL}$ ). The reaction mixture was stirred for $16 \mathrm{~h}$ at $25^{\circ} \mathrm{C}$ and vacuum filtered on an EMD Millipore support with a nylon filtration membrane $(0.22 \mu \mathrm{m}, 47 \mathrm{~mm}$, hydrophilic). The functionalized carbon powder was washed successively by distilled water. Finally the functionalized carbon was dried in an oven at $120^{\circ} \mathrm{C}$ for $16 \mathrm{~h}$. 


\subsection{Catalyst characterization technics}

Sulfur content was carried out by elemental analysis. The sample was heated to $1020^{\circ} \mathrm{C}$ using an apparatus NA2100 Protein Thermoquest. The different chemical elements were then separated by a filled chromatographic column before being detected by using a cathetometer. Catalytic sites of a functionalized solid expressed in $\mathrm{mmol} \mathrm{g}^{-1}$ can be calculated from elemental analysis according to the following formula: $1000 \times \mathrm{S} \% / \mathrm{M}(\mathrm{S})$ where $\mathrm{S} \%$ represents the sulfur weight content in a sample of $1000 \mathrm{mg}$ and $\mathrm{M}(\mathrm{S})$ refers to the molar weight of sulfur equal to $32.065 \mathrm{~g} \mathrm{~mol}^{-1}$.

The strength and distribution of acid sites of the catalysts were measured by temperatureprogrammed desorption (TPD) of ammonia $\left(\mathrm{NH}_{3}\right)$. Prior to analysis, the sample were degassed by heating up to $200{ }^{\circ} \mathrm{C}$ for $1 \mathrm{~h}$ in a He flow of $100 \mathrm{~mL} \cdot \mathrm{min}^{-1}$. After this pretreatment, the catalyst was exposed to pure anhydrous $\mathrm{NH}_{3}$ gas at $100{ }^{\circ} \mathrm{C}$ for $10 \mathrm{~min}$. Subsequently, the physisorbed ammonia on the catalyst surface was flushed with helium gas at the same temperature. Then, TPD analysis was carried out from room temperature to $800{ }^{\circ} \mathrm{C}$ with a heating rate of $10{ }^{\circ} \mathrm{C} \cdot \mathrm{min}^{-1}$ in a He flow. The desorbed $\mathrm{NH}_{3}$ was analyzed with a thermal conductivity detector (TCD).

The textural properties were determined from $\mathrm{N}_{2}$ adsorption-desorption isotherms, which were measured using a TRISTAR 3000 gas adsorption system at $-196{ }^{\circ} \mathrm{C}$. Prior to $\mathrm{N}_{2}$ adsorption, the samples were degassed overnight under secondary vacuum at $150{ }^{\circ} \mathrm{C}$. The specific surface area $\left(\mathrm{S}_{\mathrm{BET}}\right.$ in $\left.\mathrm{m}^{2} \mathrm{~g}^{-1}\right)$ was calculated using the Brunauer-Emmett-Teller (BET) method. The total pore volume was calculated at $\mathrm{P} / \mathrm{P}_{0}$ equal to 0.99 . The average pore size was calculated from the desorption isotherm branch using the Barret-Joyner-Halenda (BJH) method.

Fourier transform infrared (FT-IR) spectra were recorded on powder using a Perkin Elmer One FT-IR spectrometer with a resolution of $4 \mathrm{~cm}^{-1}$ and operating in the range of $700-4000$ $\mathrm{cm}^{-1}$ with 16 scans per spectrum.

Thermogravimetric analysis (TGA) was used to assess the thermal stability of samples. The measurements were carried out on a SDT Q600 TA Instruments apparatus from room temperature. The analysis were performed up to $700{ }^{\circ} \mathrm{C}$ (heating rate: $10{ }^{\circ} \mathrm{C} / \mathrm{min}$ ) under air (100 mL/min).

The morphology of Darco and Darco-0.50ASFL was inspected by scanning electron microscopy (SEM) using a JSM 7900F microscope operating at $1 \mathrm{kV}$ equipped with an EDS detector. 
XPS measurements were performed with a Kratos Axis Ultra DLD spectrometer using monochromatic Aluminium $\mathrm{K} \alpha$ radiation at $150 \mathrm{~W}$. The pass energy of the analyser was $20 \mathrm{eV}$ and the energy step was $0.1 \mathrm{eV}$. The XPS results were correlated using the C 1s peak at 284.6 $\mathrm{eV}$. The background was corrected with the Shirley function and Wagner sensitivity factors were used in quantitative analysis.

Raman shift measurements are performed with a HORIBA JOBIN YVON Labram HR800UV Raman Microscope with $532.4 \mathrm{~nm}$ green laser beam taking the average of 4 scans. The filters used are of type D2 or D3. The laser power to the sample is $0.15 \mathrm{~mW}$ or $0.02 \mathrm{~mW}$. The spectral window is from 50 to $4000 \mathrm{~cm}^{-1}$.

\subsection{General acetalization procedure for conventional condition with solvent}

To a $25 \mathrm{~mL}$ round-bottom flask with a stir bar were added dodecanal (1 eq; $10 \mathrm{mmol} ; 2.27$ $\mathrm{mL}$ ), ethylene glycol (2 eq; $20 \mathrm{mmol} ; 1.12 \mathrm{~mL})$, toluene $(10 \mathrm{mmol} ; 1.07 \mathrm{~mL})$ as internal standard and $5 \mathrm{~mL}$ of 2-methyltetrahydrofuran (2-MTHF) as solvent. The given heterogeneous catalyst $(0.5 \%$ weight of reactants, $15 \mathrm{mg})$ was then added to the flask. 4 parallel reactions were carried out in 4 different flaks for different reaction time $(0.5 \mathrm{~h}, 1 \mathrm{~h}, 1.5 \mathrm{~h}$, and $2 \mathrm{~h})$ at $60{ }^{\circ} \mathrm{C}$. Since the total liquid volume could change during the reaction, after the scheduled time, the reaction mixture was transferred to a $25 \mathrm{~mL}$ volumetric flask to have a constant final volume. After gauging the volumetric flask, $1 \mathrm{~mL}$ of the final suspension was recovered using a syringe and the solid catalyst was eliminated by a syringe filter. The limpid solution was then analyzed by a Hitachi Chromaster HPLC equipped with a column Touzard \& Matignon Nucleosil C8 $(250 \mathrm{~mm} * 4.6 \mathrm{~mm})$ and using a methanol/water mixture $(78: 22)$ as eluent with a flow of $0.4 \mathrm{~mL}$ $\min ^{-1}$.

\subsection{General acetalization procedure for the catalytic test in PIC condition}

To a $25 \mathrm{~mL}$ round-bottom flask with a stir bar were added dodecanal (1 eq; $10 \mathrm{mmol} ; 2.27$ $\mathrm{mL})$ and ethylene glycol (2 eq; $20 \mathrm{mmol} ; 1.12 \mathrm{~mL})$. The given heterogeneous catalyst $(0.5 \%$ weight of reactants, $15 \mathrm{mg}$ ) was then added to the flask. The emulsion was created by an Ultraturax homogenizer for one minute (10 $000 \mathrm{RPM})$. The reaction was carried out at $60{ }^{\circ} \mathrm{C}$. Since emulsions have to be broken and only monophasic solution can be analyzed by HPLC, 4 parallel reactions were carried out in 4 different flaks for different reaction time $(0.5 \mathrm{~h}, 1 \mathrm{~h}, 1.5$ $\mathrm{h}$, and $2 \mathrm{~h}$ ). After the scheduled time, $5 \mathrm{~mL}$ of 2-methyltetrahydrofuran (2-MTHF) were added to form one sole phase. Then, the suspension was transferred to a $25 \mathrm{~mL}$ volumetric flask 
combined with the addition of toluene as internal standard $(10 \mathrm{mmol} ; 1.07 \mathrm{~mL})$. The roundbottom flask was rinsed by complementary 2-MTHF ( $5 \mathrm{~mL}, 3$ times) and the liquid was collected in the volumetric flask. After gauging the volumetric flask, $1 \mathrm{~mL}$ of the final suspension was recovered using a syringe and the solid catalyst was eliminated by a syringe filter. The limpid solution was then analyzed by a Hitachi Chromaster HPLC equipped with a column Touzard \& Matignon Nucleosil C8 (250 mm*4.6mm) and using a methanol/water mixture $(78: 22)$ as eluent with a flow of $0.4 \mathrm{~mL} \mathrm{~min}^{-1}$. All compounds were detected by differential refractometer (See Fig.S1). Mass balances were accurate within 5\% in all catalytic tests. A recycling study was carried out on Darco-0.5ASFL to assess its catalytic stability. After each catalytic run, the catalyst was filtrated and washed with 2-MTHF (30 mL, 4 times). After drying at $100{ }^{\circ} \mathrm{C}$ for 4 hours, the catalyst was reused for the next run.

\subsection{General acetalization procedure for homogeneous benchmark catalyst test}

$462 \mathrm{mg}$ of p-toluenesulfonic acid monohydrate (PTSA, $2.43 \mathrm{mmol}$ ) were dissolved in $5 \mathrm{~mL}$ of 2-methyltetrahydrofuran (2-MTHF) to have a solution of 0.49 M. $35 \mu \mathrm{L}$ (1\% compared to the total biphasic volume) of this PTSA solution were added to the reaction mixture. The remaining steps without the elimination of solid catalyst is the same as the general procedure for the PIC condition.

\section{Results and discussions}

\subsection{Catalyst characterizations}

Activated charcoal Darco ${ }^{\circledR} \mathrm{KB}-\mathrm{G}$ (noted as Darco henceforth for simplification) was used as a carbonaceous support for the subsequent functionalization via diazonium chemistry because of its large specific surface area and mesoporous structure $\left(S_{\mathrm{BET}}=1345 \mathrm{~m}^{2} \mathrm{~g}^{-1}\right.$ and $\mathrm{V}_{\mathrm{p}}=1.08$ $\left.\mathrm{cm}^{3} \mathrm{~g}^{-1}\right)$. The direct anchoring of phenyl sulfonic groups $\left(\mathrm{Ph}-\mathrm{SO}_{3} \mathrm{H}\right)$ was carried out by coupling this activated charcoal with diazonium salts derived from sulfanilic acid. Firstly, catalytic hydronium ions $\left(\mathrm{H}_{3} \mathrm{O}^{+}\right)$react with sodium nitrite $\left(\mathrm{NaNO}_{2}\right)$ in water to generate nitrosonium ions. The latter once formed reacts with sulfanilic acid to obtain corresponding diazonium cations. After a chemical reduction process between the reductive carbon surface and diazonium salts, phenyl sulfonic groups are grafted onto the surface of Darco (Scheme 1).

This functionalization method was exempted from using electric current and avoided the use of concentrated sulfuric acid $\left(\mathrm{H}_{2} \mathrm{SO}_{4}\right)$ and organic solvent such as dimethylacetamide and 
dioxane [12]. Furthermore, diazonium salts previously generated were spontaneously consumed by carbonaceous materials in one pot. Room temperature $\left(25^{\circ} \mathrm{C}\right)$ was privileged in the functionalization to avoid unnecessary energy consumption although Malins et al. demonstrated that a slight increase of acidity could be observed when the functionalization temperature increased from $20{ }^{\circ} \mathrm{C}$ (acidity $=0.54 \mathrm{mmol} \mathrm{g}^{-1}$ ) to $70{ }^{\circ} \mathrm{C}$ (acidity $=0.72 \mathrm{mmol} \mathrm{g}^{-1}$ ) [8].

The influence of weight ratio sulfanilic acid (ASFL) over carbonaceous support (Darco): ASFL/Darco was investigated to determine the optimal quantity of sulfanilic acid for the functionalization procedure. A series of $\mathrm{Ph}-\mathrm{SO}_{3} \mathrm{H}$ containing solid acids were prepared with different ASFL/Darco weight ratios. The functionalized solids were denoted as Darco-nASFL, with n (from 0.10 to 1.00 ) indicating the ASFL/Darco weight ratio.

In parallel, Darco was treated under $\mathrm{N}_{2}$ at $850^{\circ} \mathrm{C}$ for 6 hours in order to remove oxygenated functions such as ester and carboxylic acid. Indeed, the oxygen content decreased from $12.6 \%$ to $7.3 \%$ after the thermal treatment. The hydrophile-lipophile balance (HLB) of the treated Darco was thus supposed to be different from Darco. The treated Darco was also used as carbonaceous support to carry out the grafting of $\mathrm{Ph}-\mathrm{SO}_{3} \mathrm{H}$ groups.

Typical $\mathrm{N}_{2}$ adsorption-desorption isotherms and pore size distributions of all solid samples are shown in Fig.S2 and Fig.S3, respectively. A type IV isotherm was observed for all solid samples with evident hysteresis loops in the $\mathrm{P} / \mathrm{P}_{0}$ range from 0.44 to 0.99 . The thermal treatment of Darco at $850{ }^{\circ} \mathrm{C}$ led to a decrease of both specific surface area and total porous volume (Table 1, entries 1 and 7). The functionalized solids based on Darco had mesoporous volumes between 0.61 and $0.98 \mathrm{~cm}^{3} \mathrm{~g}^{-1}$ and high specific surface area in the range from 747 to $1206 \mathrm{~m}^{2}$ $\mathrm{g}^{-1}$ (Table 1). The average pore diameter determined by the BJH method was around $6 \mathrm{~nm}$ for all of them. On the other side, DarcoTreated-0.50ASFL obtained from the thermal treatment of Darco at $850{ }^{\circ} \mathrm{C}$ under $\mathrm{N}_{2}$ had not only a lower specific surface area but also a smaller total porous volume compared to Darco-0.50ASFL (Table 1, entries 4 and 8). It is important to notice that the functionalization by grafting $\mathrm{Ph}-\mathrm{SO}_{3} \mathrm{H}$ groups onto either Darco or Darco treated at $850{ }^{\circ} \mathrm{C}$ led to a decrease of both specific surface area and total pore volume, which is in accordance with results reported in the literature [27]. Moreover, with the increase of ASFL/Darco weight ratio, the specific surface area and total pore volume of a functionalized solid decreased progressively.

The experimental acidity of all solid samples measured by TPD- $\mathrm{NH}_{3}$ was reported in Table $\mathbf{1}$ and each profile obtained was shown in Fig. S4. As expected, the presence of grafted species allowed to increase the acidity of the solid, the highest value was obtained with Darco- 
1.00AFSL sample $\left(0.68 \mathrm{mmol} \mathrm{g}^{-1}\right)$, which was the one synthesized with the highest quantity of sulfanilic acid used as grafting precursor. Except for Darco without phenylsulfonic groups, all solid samples exhibited a lower experimental acidity than the one expected from the sulfur content (Table 1). The presence of acid sites on Darco can be explained by the presence of carboxylic groups. The fact that the expected sulfur content were higher than the values determined by $\mathrm{NH}_{3}$ could be attributed to the formation of disulfur bridges between two neighbored phenyl sulfonic groups, as already proposed by Zhou et al. [33]. As shown in Fig S5, an increase of the ASFL / Darco weight ratio between 0 and 0.5 allowed an increase of both the sulfur content and the experimental acidity of the samples. For highest ratios (between 0.5 and 1), an increase of the quantity of sulfanilic acid had practically no influence of these values (Fig. S5). From TPD-NH $\mathrm{NH}_{3}$ profiles, the acid sites strength of all solids can be divided into three groups: weak acid sites (maximum at about $190{ }^{\circ} \mathrm{C}$ ), moderate acid sites (maximum at about $220^{\circ} \mathrm{C}$ ) and strong acid sites (maximum at about $250^{\circ} \mathrm{C}$ ). The proportion of each type of acid site was dependent on the catalyst, even if the weak acid sites always constituted the main acid sites (Table S1).

It is judicious to choose an ASFL/Darco weight ratio equal to 0.5 for the chemical functionalization since further grafting would not lead to a significant gain of acidity but a loss of specific surface area. Compared to similar works where the reduction agent hypophosphorous acid $\left(\mathrm{H}_{3} \mathrm{PO}_{2}\right)$ was not used in the functionalization procedure, our functionalized solid acids are well positioned among the results of previous study. Indeed, a previous study from Malins et al. showed that their optimal grafting procedure could functionalize $0.72 \mathrm{mmol} \mathrm{g}^{-1}$ of $\mathrm{Ph}-\mathrm{SO}_{3} \mathrm{H}$ groups on a commercial activated charcoal (AC Mesh 20-40) with a specific surface area equal to $605 \mathrm{~m}^{2} \mathrm{~g}^{-1}$ [8]. In addition, Stellwagen et al. demonstrated that an oxidized carbon nanofiber could also be functionalized and $0.77 \mathrm{mmol} \mathrm{g}^{-}$ ${ }^{1}$ of $\mathrm{Ph}-\mathrm{SO}_{3} \mathrm{H}$ groups were incorporated on the carbonaceous support under their working conditions [12]. However, even if hypophosphorous acid $\left(\mathrm{H}_{3} \mathrm{PO}_{2}\right)$ was not indispensable in the diazonium reduction with carbonaceous materials, its presence could still favor the functionalization process. For instance, Liu et al. functionalized $\mathrm{Ph}-\mathrm{SO}_{3} \mathrm{H}$ groups on an ordered mesoporous carbon (OMC) with a high specific surface area equal to $1384 \mathrm{~m}^{2} \mathrm{~g}^{-1}$ in the presence of hypophosphorous acid $\left(\mathrm{H}_{3} \mathrm{PO}_{2}\right)$ and found that the acidity could reach $1.95 \mathrm{mmol} \mathrm{g}^{-1}$ [10].

Elemental analysis indicated clearly an increase of sulfur content after grafting of $\mathrm{Ph}-\mathrm{SO}_{3} \mathrm{H}$ groups. However, it was not certain whether the increased amount of sulfur came from sulfanilic acid adsorbed by Darco or from incorporated $\mathrm{Ph}-\mathrm{SO}_{3} \mathrm{H}$ groups though new $\mathrm{C}-\mathrm{C}$ covalent bonding if we only based on elemental analysis. To clarify the situation, a mechanical mixture 
composed of sulfanilic acid and Darco was prepared for a thermogravimetric analysis (TGA) and the result was compared with Darco and Darco-0.50ASFL (Fig. S6). Firstly, all these 3 samples showed two weight losses at $456-469{ }^{\circ} \mathrm{C}$ and $483-497{ }^{\circ} \mathrm{C}$ corresponding to the carbonaceous support combustion. The melting point of sulfanilic acid is $288{ }^{\circ} \mathrm{C}$ and this compound begins to decompose from $300{ }^{\circ} \mathrm{C}$. The combustion of the sulfanilic acid was only observed on the mechanical mixture at $322{ }^{\circ} \mathrm{C}$ (Fig. S6-c) and another weight loss at $413{ }^{\circ} \mathrm{C}$ was only observed on Darco-0.50ASFL (Fig. S6-b). The weight loss at $413{ }^{\circ} \mathrm{C}$ can thus be attributed to the grafted species combustion. Assuming that the decomposed grafted species are phenyl sulfonic groups, the $20.95 \%$ weight lost corresponds to $1.33 \mathrm{mmol} \mathrm{g}^{-1}$, which is in fair good agreement with the calculated acidity of Darco-0.50ASFL (Table 1, entry 4).

X-ray photoelectron spectroscopy (XPS) analysis were conducted for sulfanilic acid, Darco, and the series of Darco-xASFL ( $\mathrm{x}=0.1,0.25,0.5,0.75$ and 1.0). The full survey spectra of Darco and Darco-0.5ASFL were presented in Fig S7. Firstly, the peak at $399.8 \mathrm{eV}$ corresponding to $-\mathrm{NH}_{2}$ was only observed in sulfanilic acid and it was absent in Darco0.50ASFL, which demonstrated clearly that the diazonium cations were successfully reduced by carbon surface and then converted to $\mathrm{N}_{2}$ (Fig.1-a). In addition, Fig. S8 didn't show any significant changes in terms of peak position and shape irrespective the quantity of grafted acidic species in $\mathrm{S} 2 \mathrm{p}$ region. The same observation can be done in $\mathrm{N}$ 1s and $\mathrm{C}$ 1s regions. Consequently, there was no doubt that $\mathrm{Ph}-\mathrm{SO}_{3} \mathrm{H}$ moieties were incorporated to carbon surface by new C-C covalent bonds instead of a physical adsorption by activated charcoal in all grafted catalysts. Indeed, the $S$ 2p core level spectrum of all Darco-xASFL presented in Fig 1-b and Fig. S8 showed a peak at $168.5 \mathrm{eV}$ which was attributed to phenyl sulfonic groups $\left(\mathrm{Ph}-\mathrm{SO}_{3} \mathrm{H}\right)$ as confirmed by other authors [18,34,35]. Although the grafting of $\mathrm{Ph}_{-} \mathrm{SO}_{3} \mathrm{H}$ groups was confirmed by the absence the peak at $399.8 \mathrm{eV}$ corresponding to $-\mathrm{NH}_{2}$, another small peak at $405.8 \mathrm{eV}$ corresponding to a nitro group $\left(-\mathrm{NO}_{2}\right)$ was detected in the $\mathrm{N} 1 \mathrm{~s}$ spectrum of Darco0.50ASFL (Fig. 1-a). By linking this result with another peak at $1071.9 \mathrm{eV}$ corresponding to the $\mathrm{Na} 1 \mathrm{~s}$ core-level (Fig. S9), the nitro group was supposed to be the residual $\mathrm{NaNO}_{2}$ which was not totally eliminated during the washing procedure especially because the nitrogen had the same atomic concentration as sodium (Fig. S7-b).

The surface composition of Darco and the functionalized solid acid Darco-0.50ASFL was investigated by FT-IR spectroscopy and compared with the IR spectrum of p-toluenesulfonic acid (PTSA) as shown in Fig.2. Darco does not have any important IR signature compared to Darco-0.50ASFL. The characteristic bands attributed to $-\mathrm{SO}_{3} \mathrm{H}$ group stretching at 1004, 1031, 1132 and $1163 \mathrm{~cm}^{-1}$ were observed on PTSA and Darco-0.50ASFL [15,18,19]. This result 
indicated that $-\mathrm{SO}_{3} \mathrm{H}$ groups were successfully incorporated onto the carbonaceous support. A strong band at $1592 \mathrm{~cm}^{-1}$ could be assigned to the aromatic ring stretching $\mathrm{v}(\mathrm{C}=\mathrm{C})$, indicating the presence of aryl rings in Darco and Darco-0.50ASFL [36].

SEM images of Darco showed that its surface was heterogeneous because both smooth and rough surface could be observed (Fig. 3). The surface modification by grafting $\mathrm{Ph}-\mathrm{SO}_{3} \mathrm{H}$ groups on the support did not change its morphology. The presence of sulfur detected by the ESD detector (Energy Dispersive X-ray Spectroscopy) was found in both smooth and rough side and this observation indicated that $\mathrm{Ph}-\mathrm{SO}_{3} \mathrm{H}$ groups dispersed randomly on the whole surface of Darco without any preference (Fig. S10). Raman spectroscopy demonstrated that the $I_{D} / I_{G}$ values did not show significant difference between Darco-0.50ASFL and Darco (Fig. S11). Consequently, the functionalization did not change the structure of Darco either.

\subsection{Catalytic properties}

The catalytic performance of Darco-0.50ASFL was assessed in the acetalization of dodecyl aldehyde with ethylene glycol at $60{ }^{\circ} \mathrm{C}$ for 2 hours towards hemiacetal and acetal with a loss of water as indicated in Scheme 2. Hemiacetal (H) and acetal (A) were successively formed in the presence of acid catalyst. All compounds in the reaction mixture were identified and showed in the HPLC chromatogram (Fig. S1). Acetal was isolated and characterized by both $\mathrm{RMN}{ }^{1} \mathrm{H}$ and ${ }^{13} \mathrm{C}$, spectra being available in ESI (Fig. S12 and S13).

In the absence of catalyst and in the presence of Darco, hemiacetal and acetal were never observed (Table 2, entries 1 and 2). Under PIC condition, it was possible to reach a conversion of dodecyl aldehyde around $75 \%$ for all functionalized solids after 2 hours (Table 2). Among the functionalized solids, Darco-0.10ASFL and DarcoTreated-0.50ASFL were less selective on fatty acetal (Table 2, entries 3 and 7), whereas the other solids could give a selectivity on fatty acetal over $90 \%$. The catalytic property of our reference solid Darco-0.50ASFL in acetalization of dodecyl aldehyde with ethylene glycol was firstly investigated in the presence of 2methyltetrahydrofuran (2-MTHF) as solvent (conventional procedure described in the experimental part). The experimental kinetic profiles of each compound in the reaction mixture were illustrated in Fig.4. As usual for consecutive reactions, the yield of hemiacetal $(\mathrm{H})$ reached a maximum and then decreased due to the formation of acetal (A). When the organic solvent was used, hemiacetal reached its maximum at $2.57 \mathrm{mmol}$ after $1 \mathrm{~h}$ and gave a static evolution afterwards. The molar amount of acetal increased with reaction time to reach $4.31 \mathrm{mmol}$ after $2 \mathrm{~h}$, corresponding to a yield equal to $43 \%$ and a selectivity equal to $65 \%$. The efficiency of 
Pickering Interfacial Catalysis (PIC) was highlighted by the use of Darco-0.50ASFL under biphasic condition stabilized by Pickering emulsions as shown in Fig.4. Indeed, the conversion of dodecyl aldehyde equal to $80 \%$ obtained by PIC technic was about $15 \%$ higher than that obtained under the conventional condition with 2-MTHF (Table 2, entries 5 and 6). This increased activity by using PIC technic could be ascribed to the formation of stable dodecyl aldehyde / ethylene glycol emulsions favoring the contact between the reagents [32,33]. Besides, both rate constants ( $\mathrm{k}_{1}$ and $\mathrm{k}_{2}$, see Scheme 1), determined by using a kinetic model, were nearly three times higher than those obtained in the conventional condition (Table 3, entries 3 and 4), which explained the better selectivity of fatty acetal under PIC condition. Moreover, the $80 \%$ of dodecyl aldehyde converted by $15 \mathrm{mg}$ of Darco-0.10ASFL gave a Productivity $(\mathrm{P})$ equal to $847 \mathrm{mmol}\left(\mathrm{mmole}^{+}\right)^{-1}$, which was good enough compared to the result previously obtained by Fang et al. using Aquivion ${ }^{\circledR}$-guar as carbonaceous solid acid in the same model reaction $\left(\mathrm{P}=950 \mathrm{mmol}\left(\text { mmole } \mathrm{H}^{+}\right)^{-1}\right)$ [19]; or by Zhou et al. [33] using phenylsulfonic groups grafted on silica $\left(\mathrm{P}=2000 \mathrm{mmol}\left(\text { mmole } \mathrm{H}^{+}\right)^{-1}\right)$. It is noteworthy to highlight that our functionalization procedure via diazonium chemistry used in the present study was easier to carry out and less energy-consuming than the other experimental procedures used previously [19,33].

In parallel, the catalytic activity of DarcoTreated-0.50ASFL obtained by grafting $\mathrm{Ph}-\mathrm{SO}_{3} \mathrm{H}$ groups onto thermally treated Darco was also investigated under PIC condition. It was found that this solid acid was less active than Darco-0.50ASFL despite the fact that their calculated acidity close to $1.10 \mathrm{mmol} \mathrm{g}^{-1}$ was very similar (Table 1, entries 4 and 8 ). Besides, the formation of acetal was less favored with DarcoTreated-0.50ASFL compared to Darco-0.50ASFL (Table $\mathbf{2}$, entries 6 and 7) in accordance with the higher $\mathrm{k}_{2} / \mathrm{k}_{1}$ ratio of Darco-0.50ASFL (Table 3, entries 4 and 5). This observation meant that the formation of acetal $\left(\mathrm{k}_{2}\right)$ became slower in the presence of DarcoTreated-0.50ASFL as catalyst. Apparently, the modification of catalyst activity should be related to the change of the HLB parameter of Darco since it lost its oxygenated functions at $850{ }^{\circ} \mathrm{C}$ and thus supposed to become less hydrophilic. Unfortunately, it was impossible to precisely characterize the HLB parameter of all functionalized solid acids by measuring contact angles because the deposited droplet of water, heptane and toluene was immediately absorbed by these solid samples.

However, we managed to determine the solid with the most appropriate HLB among the functionalized solids by correlating respectively reactions constants $\mathrm{k}_{1}$ and $\mathrm{k}_{2}$ with the weight ratio sulfanilic acid (ASFL) over carbonaceous support (Darco). According to Fig. 5, the effect of the ASFL/Darco weight ratio was the same on both $\mathrm{k}_{1}$ and $\mathrm{k}_{2}$ values. Indeed, the reaction 
rate constants increase between a weight ratio ranging from 0 to 0.25 while it follows a decreasing trend between a weight ratio ranging from 0.25 to 1.00 . An optimum is therefore observed for Darco-0.25ASFL. It should be noted that the reaction constants $\left(\mathrm{k}_{1}\right.$ and $\left.\mathrm{k}_{2}\right)$ obtained over DarcoTreated-0.50ASFL is much lower than that obtained over Darco-0.50ASFL despite the fact that the acidity deduced from the sulfur content for both solids is very close (Table 1). This result shows that prior thermal treatment on Darco before grafting process is to the detriment of the catalytic activity of the functionalized solid. Since the number of acid sites in Darco-0.25ASFL is close to that of Darco-0.50ASFL, Darco-0.75ASFL and Darco1.00ASFL, its hydrophilic lipophilic nature is probably the most suitable for achieving this reaction among the series of acid solids. Moreover, the decrease of both rate constants of the three last ones (Darco-0.50ASFL, Darco-0.75ASFL and Darco-1.00ASFL) can be explain in part with the decrease of specific surface area while their acidity remains constant (Table 1).

Finally, the benchmark catalyst p-toluenesulfonic acid (PTSA) was tested in a solvent free condition to compare with the performance of Darco-0.50ASFL. This experiment was conducted at equal calculated acid sites $(\sim 17 \mu \mathrm{mol})$ as Darco-0.50ASFL. Apparently, there was no significant difference in dodecyl aldehyde conversion between PTSA and Darco-0.50ASFL (Table 2, entries 6 and 10). However, the formation of acetal was favored in the presence of Darco-0.50ASFL since its $\mathrm{k}_{2} / \mathrm{k}_{1}$ ratio was higher compared to PTSA (Table 3, entries 4 and 8). This result could be explained by the fact that PTSA was not a good phase-transfer agent as Darco-0.50ASFL for the bi-phasic acetalization and led to a rapid phase separation after stirring. The emulsions created by PTSA could not be stabilized while Darco-0.50ASFL as an amphiphilic solid adsorbed onto the interface between the two phases and made stable droplets.

Five reaction cycles were carried out to further assess whether Darco-0.50ASFL was reusable. After each cycle, the heterogeneous catalyst was recovered by filtration and washed with large amounts of 2-MTHF then dried at $100{ }^{\circ} \mathrm{C}$ for 4 hours before the next catalytic run. The conversion of dodecyl aldehyde as well as the sulfur content after each recycling were shown in Fig.6. The gradual slight leaching of phenyl sulfonic groups $\left(\mathrm{Ph}-\mathrm{SO}{ }_{3} \mathrm{H}\right)$ from Darco after each reaction cycle was observed and the sulfur content decreased by nearly $10 \%$ from $3.55 \%$ to $3.21 \%$ after the fifth reaction cycle. Moreover, the XPS S $2 p$ spectra of the used catalyst is similar to the fresh catalyst one (Fig. S6). It can be concluded that most part of Ph$\mathrm{SO}_{3} \mathrm{H}$ groups grafted by diazonium chemistry remained attached to the carbonaceous support under our working conditions. However, as described in precedent studies, the leaching of sulfonic acid groups is the main problem of carbon-based solid [37,12,8]. Nevertheless, the moderate deactivation of Darco-0.50ASFL due to the leaching effect had slight influence on 
the conversion of dodecyl aldehyde since these 5 catalytic runs allowed a very similar conversion of dodecyl aldehyde around $80 \%$.

\section{Conclusion:}

A series of solid acids with large specific surface area was developed by grafting phenyl sulfonic groups $\left(\mathrm{Ph}_{-} \mathrm{SO}_{3} \mathrm{H}\right)$ onto Darco ${ }^{\circledR} \mathrm{KB}-\mathrm{G}$ in water under mild conditions $\left(25^{\circ} \mathrm{C}, 16 \mathrm{~h}\right)$. The amphiphilic solid Darco-0.50ASFL efficiently carried out the solvent-free acetalization between immiscible dodecyl aldehyde and ethylene glycol at $60{ }^{\circ} \mathrm{C}$. Compared to the conventional solvent condition, the genesis of Pickering emulsions allowed nearly 3 times higher reaction constants. Darco-0.50ASFL could be reused for 5 consecutive catalytic runs by simple filtration and washing procedure and it did not show significant loss of sulfur content after 5 catalytic runs.

\section{Acknowledgement}

Minrui Xu acknowledges Solvay and ANRT (Association Nationale de Recherche et de Technologie) for a CIFRE PhD fellowship. Jean-Marc Clacens and Frédéric Richard acknowledge financial support from the European Union (ERDF) and "Région Nouvelle Aquitaine". Julie Rousseau is acknowledged for SEM experiments, Nadia Guignard is acknowledged for Raman experiments and Christine Canaff is acknowledged for XPS experiments. 


\section{References:}

[1] J.H. Clark, Acc. Chem. Res. 35 (2002) 791-797.

[2] I.K. Mbaraka, D.R. Radu, V.S.-Y. Lin, B.H. Shanks, J. Catal. 219 (2003) 329-336.

[3] I.K. Mbaraka, B.H. Shanks, J. Catal. 229 (2005) 365-373.

[4] Y. Zhang, A.A. Tamijani, M.E. Taylor, B. Zhi, C.L. Haynes, S.E. Mason, R.J. Hamers, J. Am. Chem. Soc. 141 (2019) 8277-8288.

[5] F. Rodríguez-reinoso, Carbon 36 (1998) 159-175.

[6] A. Onda, T. Ochi, K. Yanagisawa, Green Chem. 10 (2008) 1033-1037.

[7] X.-Y. Liu, M. Huang, H.-L. Ma, Z.-Q. Zhang, J.-M. Gao, Y.-L. Zhu, X.-J. Han, X.-Y. Guo, Molecules 15 (2010) 7188-7196.

[8] K. Malins, V. Kampars, J. Brinks, I. Neibolte, R. Murnieks, Appl. Catal. B: Env. 176-177 (2015) 553-558.

[9] X. Wang, R. Liu, M.M. Waje, Z. Chen, Y. Yan, K.N. Bozhilov, P. Feng, Chem. Mater. 19 (2007) 2395-2397.

[10] R. Liu, X. Wang, X. Zhao, P. Feng, Carbon 46 (2008) 1664-1669.

[11] M. Weissmann, S. Baranton, J.-M. Clacens, C. Coutanceau, Carbon 48 (2010) 2755-2764.

[12] D.R. Stellwagen, F. van der Klis, D.S. van Es, K.P. de Jong, J.H. Bitter, ChemSusChem 6 (2013) 1668-1672.

[13] J. Ji, G. Zhang, H. Chen, S. Wang, G. Zhang, F. Zhang, X. Fan, Chem. Sci. 2 (2011) 484487.

[14] M. Toda, A. Takagaki, M. Okamura, J.N. Kondo, S. Hayashi, K. Domen, M. Hara, Nature 438 (2005) 178.

[15] S. Suganuma, K. Nakajima, M. Kitano, D. Yamaguchi, H. Kato, S. Hayashi, M. Hara, J. Am. Chem. Soc. 130 (2008) 12787-12793.

[16] J.R. Kastner, J. Miller, D.P. Geller, J. Locklin, L.H. Keith, T. Johnson, Cat. Tod. 190 (2012) 122-132.

[17] A. Aldana-Pérez, L. Lartundo-Rojas, R. Gómez, M.E. Niño-Gómez, Fuel 100 (2012) 128138.

[18] R. Jia, J. Ren, X. Liu, G. Lu, Y. Wang, J. Mater. Chem. A 2 (2014) 11195-11201.

[19] W. Fang, Z. Fan, H. Shi, S. Wang, W. Shen, H. Xu, J.-M. Clacens, F.D. Campo, A. Liebens, M. Pera-Titus, J. Mater. Chem. A 4 (2016) 4380-4385.

[20] A.V. Nakhate, G.D. Yadav, ACS Sustainable Chem. Eng. 4 (2016) 1963-1973.

[21] N. Kornblum, G.D. Cooper, J.E. Taylor, J. Am. Chem. Soc. 72 (1950) 3013-3021.

[22] J.L. Bahr, J.M. Tour, Chem. Mater. 13 (2001) 3823-3824.

[23] C.A. Dyke, J.M. Tour, J. Am. Chem. Soc. 125 (2003) 1156-1157.

[24] A. Adenier, E. Cabet-Deliry, A. Chaussé, S. Griveau, F. Mercier, J. Pinson, C. VautrinUl, Chem. Mater. 17 (2005) 491-501.

[25] P. Doppelt, G. Hallais, J. Pinson, F. Podvorica, S. Verneyre, Chem. Mater. 19 (2007) 4570-4575.

[26] M. Toupin, D. Bélanger, J. Phys. Chem. C 111 (2007) 5394-5401.

[27] M. Toupin, D. Bélanger, Langmuir 24 (2008) 1910-1917.

[28] P. Abiman, G.G. Wildgoose, R.G. Compton, J. Phys. Org. Chem. 21 (2008) 433-439.

[29] G.L.C. Paulus, Q.H. Wang, M.S. Strano, Acc. Chem. Res. 46 (2013) 160-170.

[30] B.D. Assresahegn, T. Brousse, D. Bélanger, Carbon 92 (2015) 362-381.

[31] M. Gomberg, W.E. Bachmann, J. Am. Chem. Soc. 46 (1924) 2339-2343.

[32] M. Pera-Titus, L. Leclercq, J.-M. Clacens, F. De Campo, V. Nardello-Rataj, Angew. Chem. Int. Ed. 54 (2015) 2006-2021.

[33] W.-J. Zhou, L. Fang, Z. Fan, B. Albela, L. Bonneviot, F. De Campo, M. Pera-Titus, J.-M. Clacens, J. Am. Chem. Soc. 136 (2014) 4869-4872. 
[34] W.-Y. Lou, M.-H. Zong, Z.-Q. Duan, Bior. Tech. 99 (2008) 8752-8758.

[35] B. Zhang, J. Ren, X. Liu, Y. Guo, Y. Guo, G. Lu, Y. Wang, Catal. Commun. 11 (2010) 629-632.

[36] P. Larkin, in: Infrared and Raman Spectroscopy, Elsevier, 2011, pp. 73-115.

[37] X. Mo, D.E. López, K. Suwannakarn, Y. Liu, E. Lotero, J.G. Goodwin, C. Lu, J. Catal. 254 (2008) 332-338. 


\section{Figure captions}

Fig.1 XPS N 1s spectra of Darco-0.50ASFL and sulfanilic acid (a) and XPS S 2p spectrum of Darco-0.50ASFL (b)

Fig.2 FT-IR spectra of Darco and Darco-0.50ASFL compared with the FT-IR spectrum of PTSA

Fig.3 SEM images of Darco and Darco-0.50ASFL: a) Darco-0.50ASFL with a magnification of 2000; b) Darco-0.50ASFL with a magnification of 5000; c) Darco with a magnification of 2000; d) Darco with a magnification of 5000

Fig.4 Experimental kinetic profiles in solvent free and conventional conditions: experimental values obtained in solvent free condition, $(\diamond)$ experimental values obtained in conventional condition. Model kinetic profiles in solvent free and conventional conditions: (-) solid line for model molar quantity in solvent free condition, (...) dotted line for model molar quantity in conventional condition. All values related to dodecyl aldehyde highlighted in red, hemiacetal in green and acetal in blue. Reaction conditions: $60{ }^{\circ} \mathrm{C}$, using $15 \mathrm{mg}$ of Darco0.50ASFL.

Fig.5 (a) Correlation between reaction constant $\mathrm{k}_{1}$ and ASFL/Darco weight ratio and (b) Correlation between reaction constant $\mathrm{k}_{2}$ and ASFL/Darco weight ratio

Fig.6 Recycling study of Darco-0.50ASFL $\left(60^{\circ} \mathrm{C}, 2 \mathrm{~h}\right)$ and its sulfur content after each catalytic run 
Table 1. Physico-chemical properties of Darco, Darco treated at $850{ }^{\circ} \mathrm{C}$ under $\mathrm{N}_{2}$ and all

\section{functionalized solid acids}

\begin{tabular}{ccccccc}
\hline Entry & Solid & $\begin{array}{c}\text { Sulfur } \\
\text { content }^{[\mathbf{a}]} \\
\left(\mathrm{mmol} \mathrm{g}^{-1}\right)\end{array}$ & $\begin{array}{c}\text { Experimental } \\
\text { acidity }^{[\mathbf{b}]} \\
\left(\mathbf{m m o l ~}^{-1}\right)\end{array}$ & $\begin{array}{c}\mathrm{S}_{\mathrm{BET}}{ }^{[\mathrm{c}]} \\
\left(\mathrm{m}^{2} \mathrm{~g}^{-1}\right)\end{array}$ & $\begin{array}{c}\mathrm{V}_{\mathrm{p}}{ }^{[\mathrm{d}]} \\
\left(\mathrm{cm}^{3} \mathrm{~g}^{-1}\right)\end{array}$ & $\begin{array}{c}\mathrm{d}_{\mathrm{p}}{ }^{[\mathrm{e}]} \\
(\mathrm{nm})\end{array}$ \\
\hline 1 & Darco & 0 & $\mathbf{0 . 1 4}$ & 1345 & 1.08 & 6.4 \\
2 & Darco-0.10ASFL & 0.59 & $\mathbf{0 . 2 1}$ & 1206 & 0.98 & 6.2 \\
3 & Darco-0.25ASFL & 0.86 & $\mathbf{0 . 5 6}$ & 1021 & 0.83 & 6.4 \\
4 & Darco-0.50ASFL & 1.10 & $\mathbf{0 . 6 2}$ & 935 & 0.76 & 6.2 \\
5 & Darco-0.75ASFL & 1.13 & $\mathbf{0 . 6 3}$ & 807 & 0.65 & 6.3 \\
6 & Darco-1.00ASFL & 1.17 & $\mathbf{0 . 6 8}$ & 747 & 0.61 & 6.3 \\
7 & Treated Darco & 0 & $\mathbf{0 . 1 0}$ & 1157 & 0.94 & 6.2 \\
8 & DarcoTreated- & 1.16 & $\mathbf{0 . 5 8}$ & 578 & 0.52 & 6.2
\end{tabular}

[a] Sulfur content calculated from elemental analysis. [b] Experimental acidity measured from TPD of $\mathrm{NH}_{3}$. [c] Specific surface area determined by BET method. [d] Total porous volume calculated at $\mathrm{P} / \mathrm{P}^{\circ}=0.99$. [e] Average pore diameter calculated from the desorption isotherm branch using the BarretJoyner-Halenda (BJH) method. 
Table 2. Acetalization of dodecyl aldehyde $(10 \mathrm{mmol})$ with ethylene glycol $(20 \mathrm{mmol})$ catalyzed by different catalysts and in different conditions $\left(60^{\circ} \mathrm{C}, 2 \mathrm{~h}, 15 \mathrm{mg}\right.$ of solid catalyst, $17 \mu \mathrm{mol}$ for PTSA)

\begin{tabular}{|c|c|c|c|c|c|}
\hline Entry & Solid & Condition $^{[\mathrm{a}]}$ & $\begin{array}{c}\text { Conversion }^{[\mathrm{b}]} \\
(\%)\end{array}$ & $\begin{array}{c}\text { Selectivity }(\text { Hemiacetal })^{[\mathrm{c}]} \\
(\%)\end{array}$ & $\begin{array}{c}\text { Selectivity } \\
\text { (Acetal) }^{[\mathrm{c}]} \\
(\%)\end{array}$ \\
\hline 1 & Blank (no catalyst) & Solvent free & 0 & 1 & 1 \\
\hline 2 & Darco & Solvent free & 0 & / & / \\
\hline 3 & Darco-0.10ASFL & $\mathrm{PIC}$ & 75 & 25 & 75 \\
\hline 4 & Darco-0.25ASFL & $\mathrm{PIC}$ & 83 & 3 & 97 \\
\hline 5 & Darco-0.50ASFL & With Solvent & 66 & 35 & 65 \\
\hline 6 & Darco-0.50ASFL & $\mathrm{PIC}$ & 80 & 4 & 96 \\
\hline 7 & DarcoTreated-0.50ASFL & $\mathrm{PIC}$ & 73 & 31 & 69 \\
\hline 8 & Darco-0.75ASFL & $\mathrm{PIC}$ & 78 & 8 & 92 \\
\hline 9 & Darco-1.00ASFL & $\mathrm{PIC}$ & 87 & 7 & 93 \\
\hline 10 & PTSA & Solvent free & 74 & 19 & 81 \\
\hline
\end{tabular}

[a] Solvent free condition: the 2 non miscible phases were mixed by Ultraturax (10 000 RPM) for 1 minute without solid then stirred by a stirring bar for 2 hours; With solvent condition: the 2 non miscible phases were diluted in $5 \mathrm{~mL}$ of 2 -MTHF, forming a homogeneous phase and stirred by a stirring bar for 2 hours; PIC condition: the 2 non miscible phases were mixed by Ultraturax (10 000 RPM) for 1 minute in the presence of solid then stirred by a stirring bar for 2 hours [b] Conversion of dodecyl aldehyde after 2 hours calculated based on HPLC data. [c] Product selectivity after 2 hours calculated based on HPLC data. 
Table 3. Reaction constants of the 2-step acetalization

\begin{tabular}{ccccc}
\hline Entry & Catalyst & Condition & $\begin{array}{c}\mathrm{k}_{1}{ }^{[\mathrm{a}]} \\
\left(\mathrm{mmol}^{-1} \mathrm{~h}^{-1}\right)\end{array}$ & $\begin{array}{c}\mathrm{k}_{2}{ }^{[\mathrm{b}]} \\
\left(\mathrm{h}^{-1}\right)\end{array}$ \\
\hline 1 & Darco-0.10ASFL & PIC & 0.13 & 0.41 \\
2 & Darco-0.25ASFL & PIC & 0.22 & 1.07 \\
3 & Darco-0.50ASFL & With solvent & 0.06 & 0.23 \\
4 & Darco-0.50ASFL & PIC & 0.15 & 0.75 \\
5 & DarcoTreated-0.50ASFL & PIC & 0.10 & 0.34 \\
6 & Darco-0.75ASFL & PIC & 0.17 & 0.69 \\
7 & Darco-1.00ASFL & PIC & 0.12 & 0.55 \\
8 & PTSA & Solvent-free & 0.13 & 0.50 \\
\hline
\end{tabular}

[a] Reaction constant of dodecyl aldehyde conversion. [b] Reaction constant of acetal formation. Reaction conditions: acetalization of dodecyl aldehyde $(10 \mathrm{mmol})$ with ethylene glycol $(20 \mathrm{mmol})$ catalyzed by different catalysts at $60{ }^{\circ} \mathrm{C}$ for $2 \mathrm{~h}$, using $15 \mathrm{mg}$ of solid catalyst, or $17 \mu \mathrm{mol}$ for PTSA. 
Fig.1

XPS N 1s spectra of Darco-0.50ASFL and sulfanilic acid (a) and XPS S 2p spectrum of Darco$0.50 \mathrm{ASFL}(\mathrm{b})$
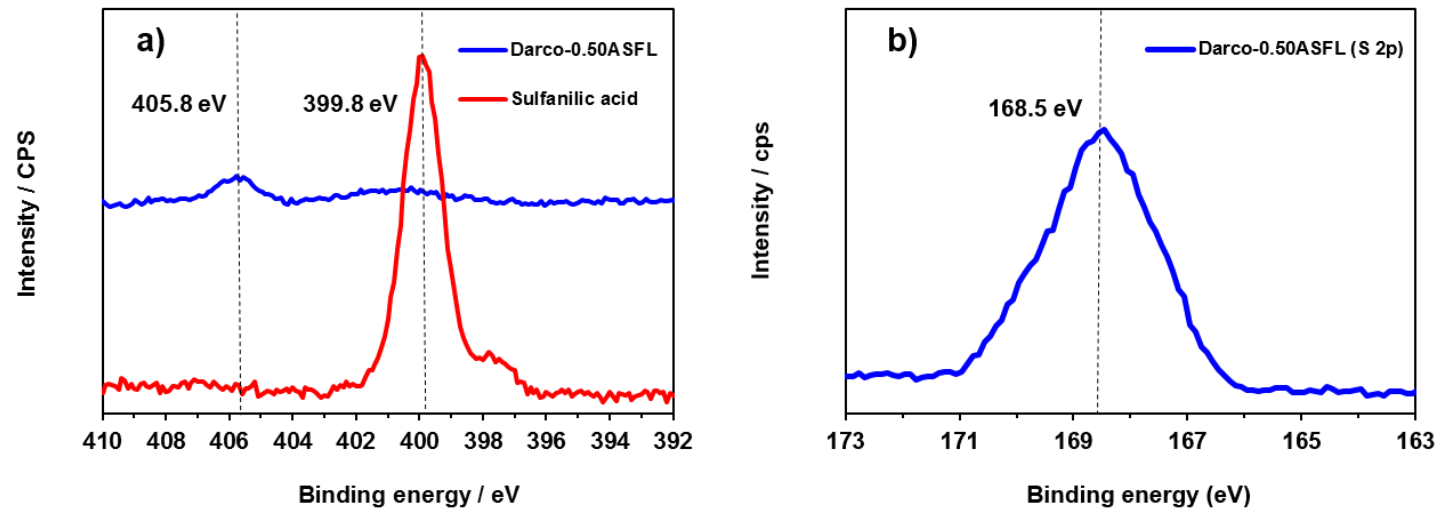
Fig.2

FT-IR spectra of Darco and Darco-0.50ASFL compared with the FT-IR spectrum of PTSA

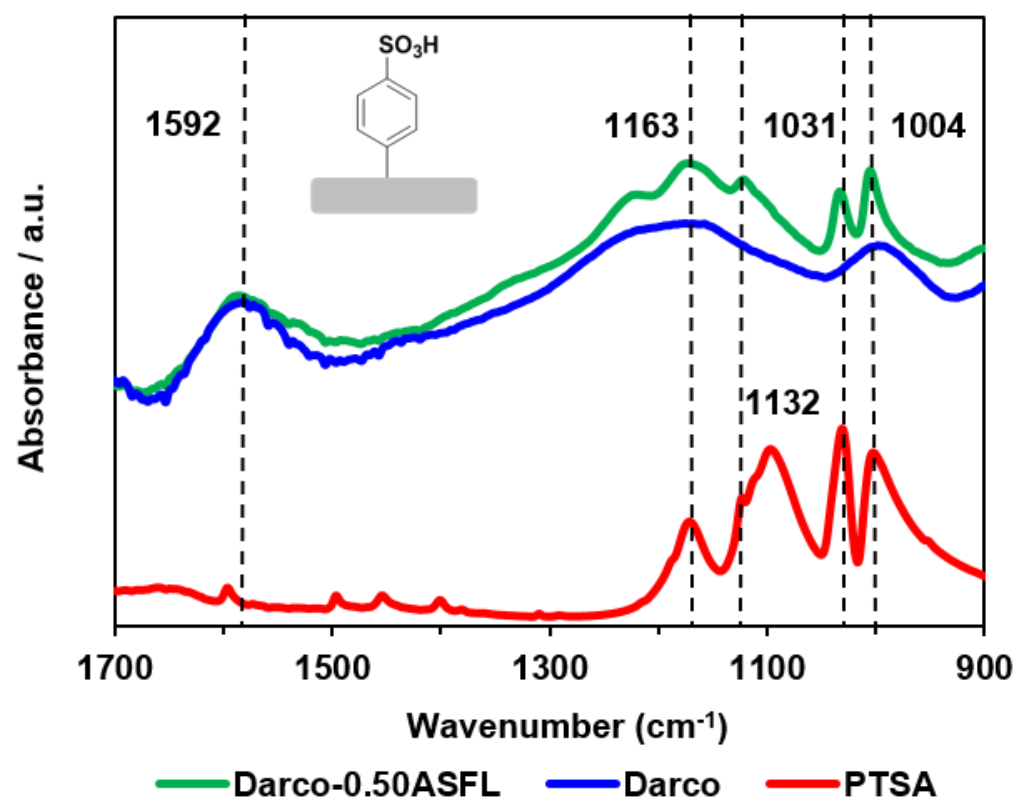




\section{Fig. 3}

SEM images of Darco and Darco-0.50ASFL: a) Darco-0.50ASFL with a magnification of 2000;

b) Darco-0.50ASFL with a magnification of 5000; c) Darco with a magnification of 2000; d)

Darco with a magnification of 5000

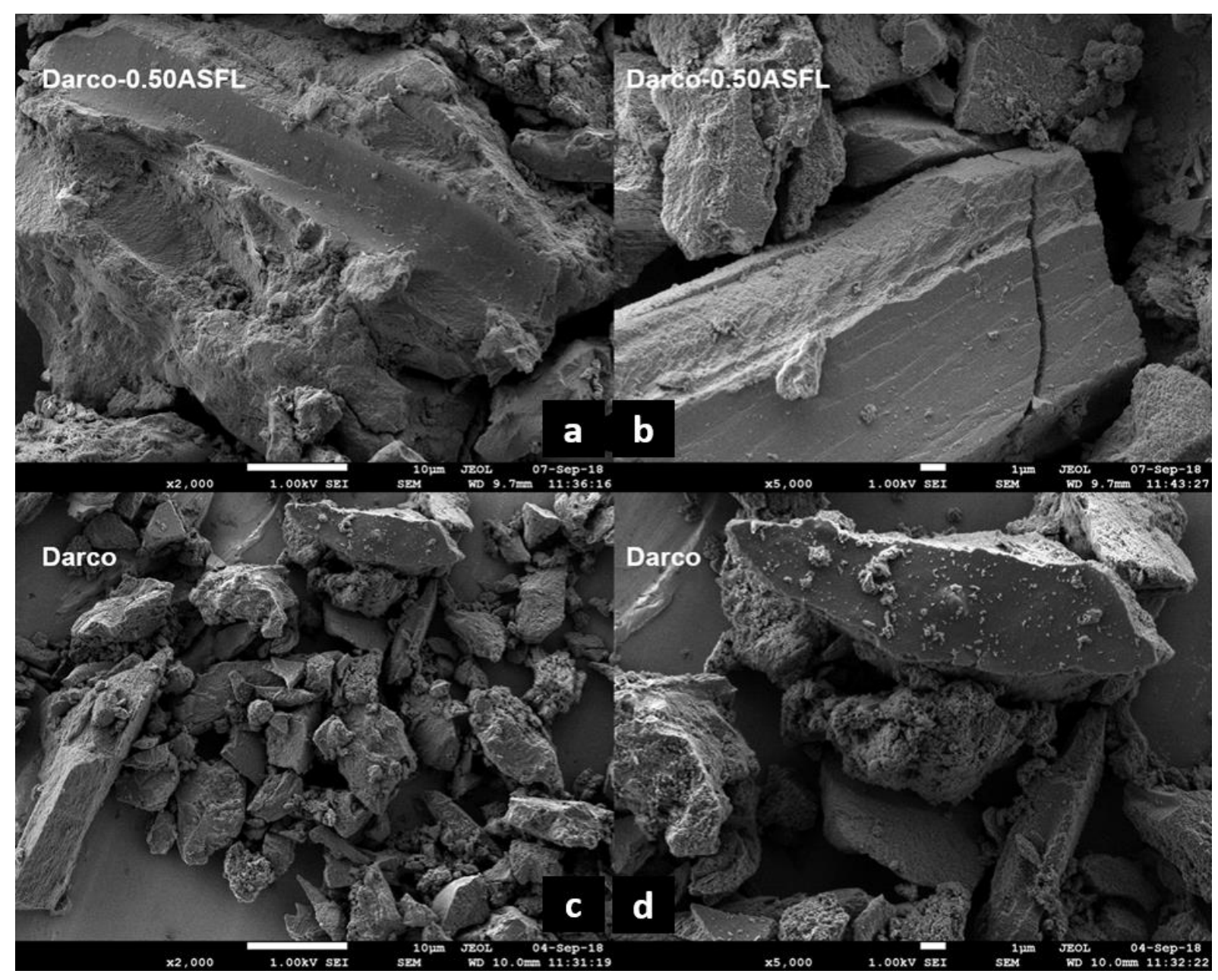




\section{Fig. 4}

Experimental kinetic profiles in solvent free and conventional conditions: (๑) experimental values obtained in solvent free condition, $(\diamond)$ experimental values obtained in conventional condition. Model kinetic profiles in solvent free and conventional conditions: (-) solid line for model molar quantity in solvent free condition, (...) dotted line for model molar quantity in conventional condition. All values related to dodecyl aldehyde highlighted in red, hemiacetal in green and acetal in blue. Reaction conditions: $60{ }^{\circ} \mathrm{C}$, using $15 \mathrm{mg}$ of Darco-0.50ASFL.

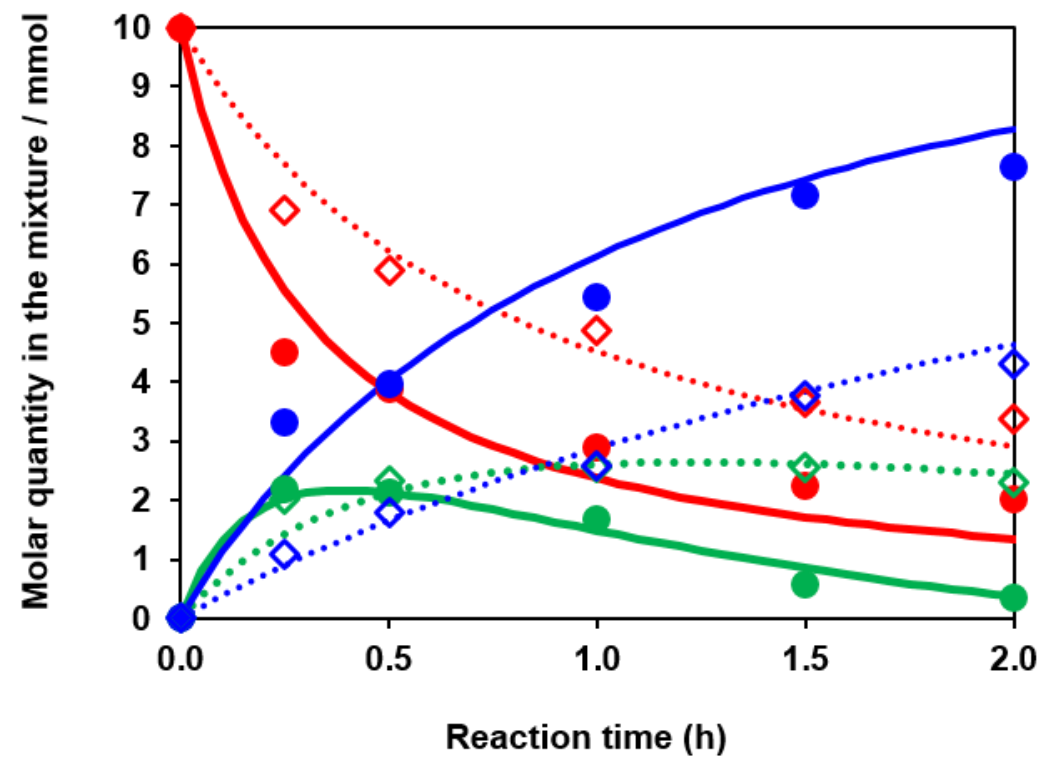


Fig. 5

Acetalization of dodecyl aldehyde $(10 \mathrm{mmol})$ with ethylene glycol $(20 \mathrm{mmol})$ catalyzed by different catalysts. Reaction conditions: $60^{\circ} \mathrm{C}, 2 \mathrm{~h}$, using $15 \mathrm{mg}$ of solid catalyst.

(a) Correlation between reaction constant $\mathrm{k}_{1}$ and ASFL/Darco weight ratio

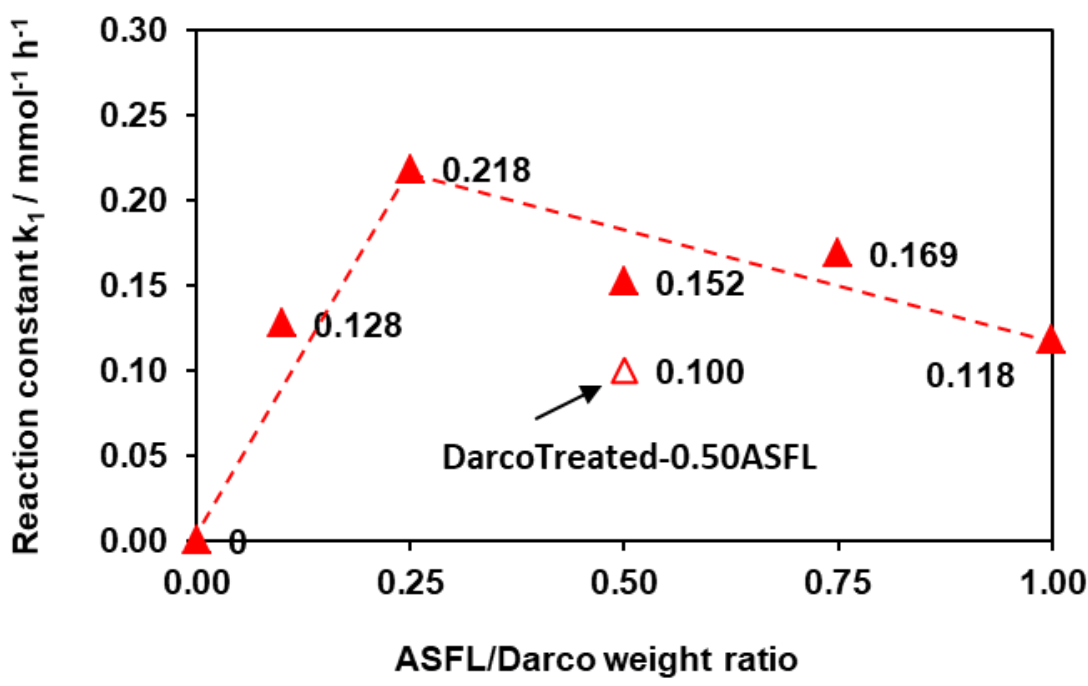

(b) Correlation between reaction constant $\mathrm{k}_{2}$ and ASFL/Darco weight ratio

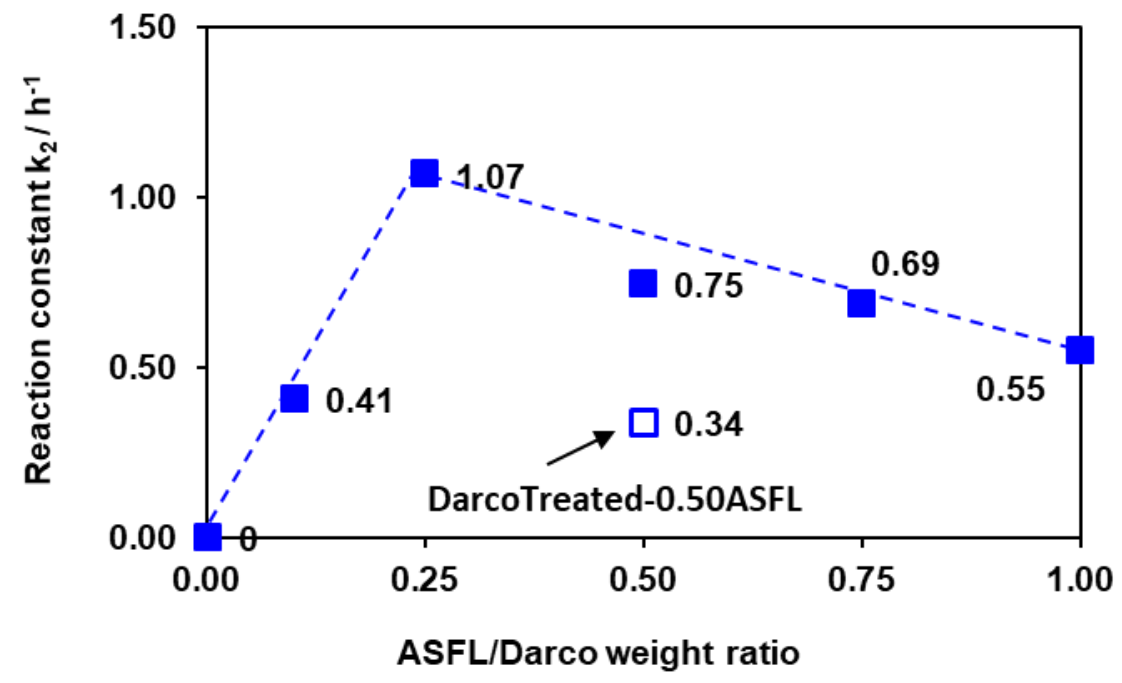


Fig. 6

Recycling study of Darco-0.50ASFL $\left(60^{\circ} \mathrm{C}, 2 \mathrm{~h}\right)$ and its sulfur content after each catalytic run. Reaction conditions: acetalization of dodecyl aldehyde $(10 \mathrm{mmol})$ with ethylene glycol (20 mmol) catalyzed by different catalysts at $60^{\circ} \mathrm{C}, 2 \mathrm{~h}$, using $15 \mathrm{mg}$ of Darco-0.50ASFL.

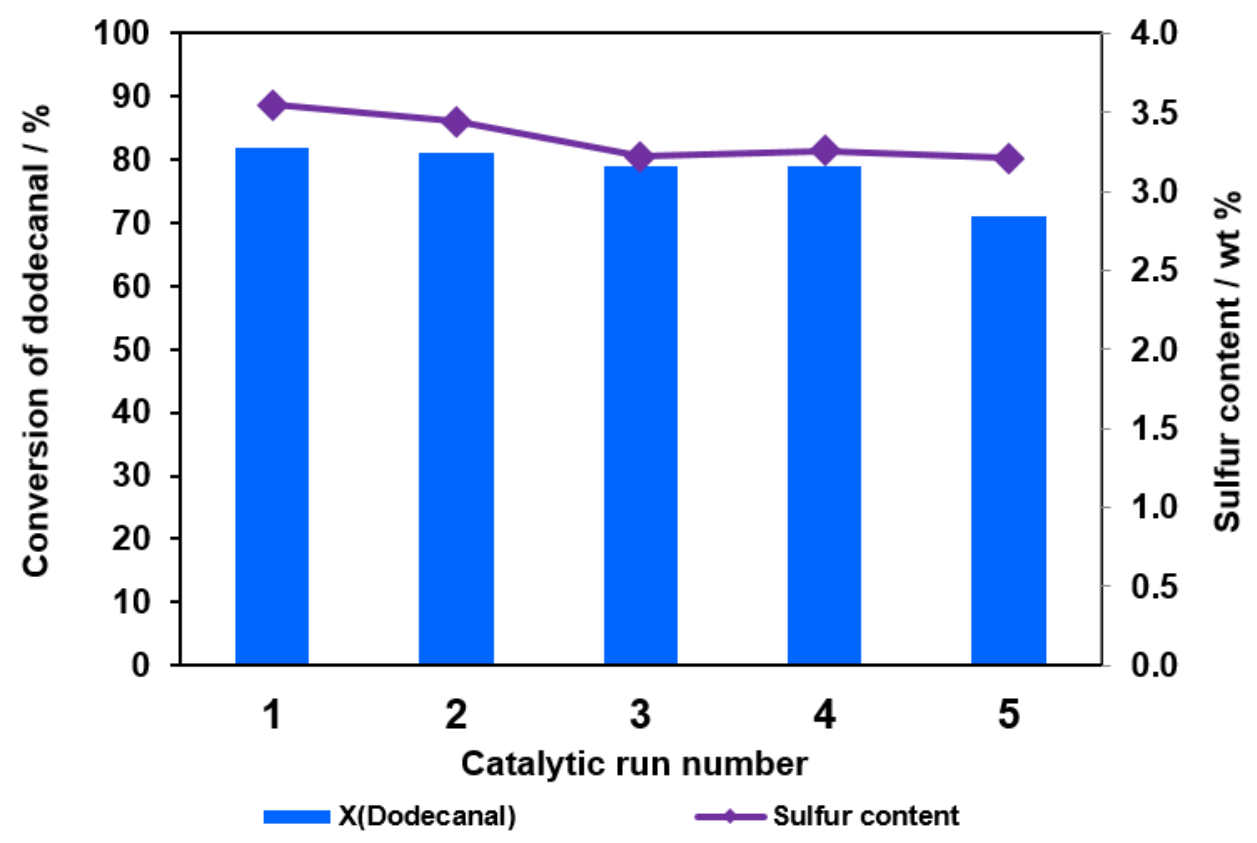




\section{Scheme 1:}

Schematic illustration of the synthesis of carbon-based solid acid

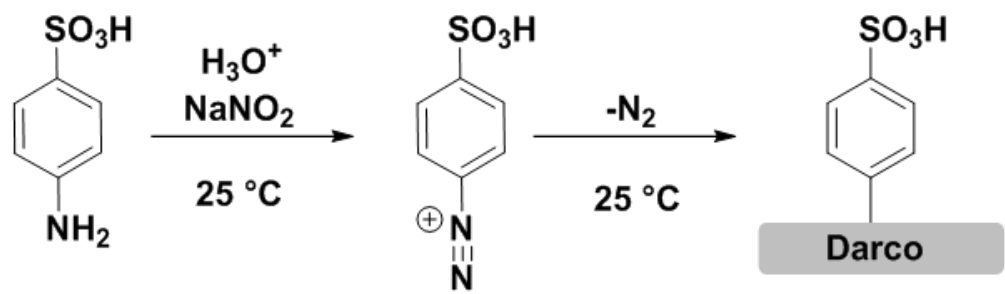

\section{Scheme 2:}

Acetalization of dodecyl aldehyde with ethylene glycol leading to Hemiacetal (1-(2hydroxyethoxy)dodecan-1-ol), Acetal (2-undecyl-1,3-dioxolane) and water

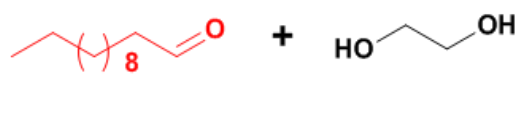

Dodecyl aldehyde D
Ethylene glycol

EG

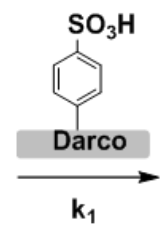

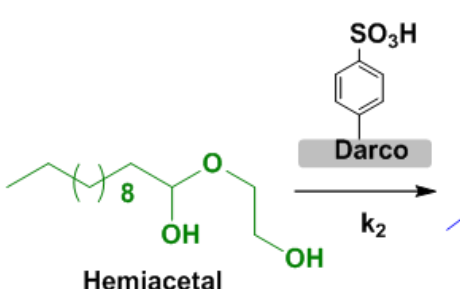

H

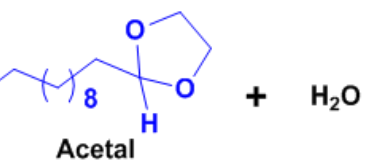

A 